\title{
The possibilities of a portable low-budget three-dimensional stereophotogrammetry system in neonates: a prospective growth analysis and analysis of accuracy
}

Lucas M. Ritschl $1^{1 *}$, Maximilian Roth ${ }^{1,2}$, Andreas M. Fichter ${ }^{1}$, Fabienna Mittermeier ${ }^{1}$, Bettina Kuschel ${ }^{3}$, Klaus-Dietrich Wolff ${ }^{1}$, Florian D. Grill ${ }^{1+}$ and Denys J. Loeffelbein ${ }^{2+}$

\begin{abstract}
Background: With the technical development, portable three-dimensional (3D) photogrammetry systems are becoming more en vogue because of cost-effectiveness and comparable accuracy to common stationary 3D systems. The purpose of the study was to evaluate the feasibility and accuracy of a low-budget portable system for 3D image acquisition with special regard to the gracile nasal region in neonates. Furthermore, the study aimed to establish a 3D data set of the first 180 days post partum.

Methods: Thirty-three healthy, full-term newborn were enrolled and 3D photographs were prospectively taken monthly with a portable low-budget 3D stereophotogrammetry system (FUEL3D ${ }^{\circledR}$ SCANIFY ${ }^{\circledast}$ ) for six months. In the third month, age-matched and corresponding 3D models were acquired by taking an impression of the perinasal area. The resulting plaster models were scanned (3Shape D700, 3Shape ${ }^{\oplus} \mathrm{A} / \mathrm{S}$, Denmark). Three examiners analyzed independently 21 defined landmarks of the generated Standard Tessellation Language files with regard to accuracy

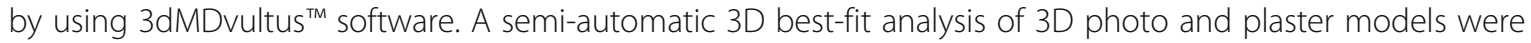
performed by using Geomagic ${ }^{\oplus}$ and the Root Mean Squared (RMS) errors were calculated.

Results: Statistically significant changes of midfacial distances and angles with a focus on nasal growth during the first 180 days postpartum could be specified in absolute and relative dimensions. Best-fit analysis in the third month revealed a RMS error of $0.72 \pm 0.22 \mathrm{~mm}$ with a mean standard deviation of $0.71 \pm 0.21 \mathrm{~mm}$.

Conclusions: The analyzed portable 3D stereophotogrammetry system is a feasible methodology with good accuracy, even in newborn. A description of the growth as well as the establishment of a 3D data set was performed. Its implementation for basic documentation for example in cleft patients is possible and might reduce the need for impressions and facilitate the communications with parents and the interdisciplinary team.
\end{abstract}

Keywords: Three-dimensional (3D) photogrammetry, Facial analysis

\footnotetext{
* Correspondence: lucas.ritschl@tum.de

Florian D. Grill and Denys J. Loeffelbein shared last authorship.

${ }^{\dagger}$ Florian D. Grill and Denys J. Loeffelbein contributed equally to this work.

'Department of Oral and Maxillofacial Surgery, Klinikum rechts der Isar,

Technische Universität München, Ismaningerstr. 22, D-81675 Munich,

Germany

Full list of author information is available at the end of the article
}

(C) The Author(s). 2018 Open Access This article is distributed under the terms of the Creative Commons Attribution 4.0 International License (http://creativecommons.org/licenses/by/4.0/), which permits unrestricted use, distribution, and reproduction in any medium, provided you give appropriate credit to the original author(s) and the source, provide a link to the Creative Commons license, and indicate if changes were made. The Creative Commons Public Domain Dedication waiver (http://creativecommons.org/publicdomain/zero/1.0/) applies to the data made available in this article, unless otherwise stated. 


\section{Background}

Photo documentation of the face is of fundamental importance for follow-up, communication with patients or parents, illustrative purposes in lectures or medico-legal requirements, and nowadays in surgical planning. Two-dimensional (2D) images have been and are the gold standard for this purpose and can be used to reliably assess phenotypic severity of craniofacial anomalies as stated earlier [1-5]. Considering the drawbacks of conventional 2D photography in picturing three-dimensional (3D) structures and the patient's exposure to radiation in traditional 3D surface recognition as cephalometry, cone beam scan or computed tomography, non-invasive 3D surface imaging has become more popular in the last decade [6]. It enables non-invasive preoperative illustrative, virtual documentation, planning and simulation $[7,8]$. Beside 2D analysis, 3D photography can also be used to analyze facial soft tissue asymmetry [9-11]. More recently, 3D photogrammetry is adapted in the post-operative follow-up of the young patients presenting with cleft lip and palate and/or craniosynostosis [12-15]. But only a minority of studies used portable, hand-held 3D systems including the Artec Eva Scan imaging system, the Vectra H1 system or the M4D Scan system [16-19]. The accuracy is reported to be comparable to common stationary $3 \mathrm{D}$ photogrammetry systems and to be sufficient for the most clinical applications [19-21].

The purpose of this study was to analyze a low-budget portable 3D photogrammetry system costing less than $1500 €$ with a shorter acquisition time compared to the above-mentioned portable systems. Herein a special attention is being paid to accuracy in scanning the nose and the perinasal region. Furthermore, we aimed to evaluate the suitability and feasibility of the application of the system with regard to facial scans in neonates and to describe the growth. Finally the application and integration on neonatal documentation is presented.

\section{Methods}

\section{Ethical statement and participant acquisition}

The study followed the Declaration of Helsinki on medical protocol and ethics and the regional Ethical Review Board of the technical university of Munich approved the study (approval number: 13/16 S). Written participant consent was obtained from the parents and the data collected were pseudonymized. Only healthy full-term Caucasian neonates with unremarkable screening examinations (U1 and U2) were enrolled in collaboration with the Section of obstetrics, Frauenklinik, Klinikum rechts der Isar, Technische Universität München, Germany.

\section{Facial scans and control model generation}

All enrolled neonates were prospectively scanned monthly for a period of the first six postnatal months (180 days), with the first scan to be obtained at the first day postpartum. A variation of \pm five days was accepted for the following monthly appointments. Otherwise the taken 3D photo was excluded from analysis. The neonate was also excluded from further analysis, if more than one 3D photo was missed in follow-up. This resulted optimally in six 3D photos per participant in total.

Additionally, a conventional impression of the nose was taken simultaneously to the third facial 3D photo for the generation of a corresponding control model. As previously described, a bluish, semi-transparent a-silicone (Memosil ${ }^{\circ}$ 2; Kulzer GmbH; Germany) was used for taking the impression [22]. The corresponding plaster models were produced within one hour after impression taking to overcome technical inaccuracy [23]. Following, the plaster models were scanned with a common dental Laser-Scanner (3Shape D700, 3Shape ${ }^{\circledR}$ A/S, Denmark) for Standard Tessellation Language (.STL) file generation and further analysis (see below). The dental Laser-Scanner worked with two integrated cameras (1.3 Megapixels) and a tri-axial joint rotation system so that even deep notches and cavities could be scanned. This quickly provided high resolution scans with an accuracy of $20 \mu \mathrm{m}$, according to the manufacturer's instructions.

\section{Low-budget portable 3D photogrammetry system}

The analyzed 3D photogrammetry system was the FUEL3D $^{\circ}$ SCANIFY $^{\odot}$ system scanner, equipped with an adaptable commercially available tablet with a 32-bit Microsoft $^{\oplus}$ Windows $^{\oplus} 8$ version for data and operational processing. As given in the manufacturer's instructions [24], the scanner consists of two 3.5 megapixel color-cameras with vertical orientation, three xenon flashlights, three LED searchlights and two release buttons. The integrated hardware delivers a capture speed of approximately $0.1 \mathrm{~s}$. The focus is precalibrated and captures $3 \mathrm{D}$ data at a diagonal of circa $40 \mathrm{~cm}$ with a resolution of up to $350 \mu \mathrm{m}$ resulting in up to 375,000 polygons per scan. A white plastic disc with a precisely imprinted black square, surrounding fine lines and one crescent-shaped side marking is needed as a target reference. The target is recognized and the automatic dimensioning is ensured.

The 3D scans were further reprocessed by the corresponding software FUEL3D ${ }^{\circ}$ Studio 2.2 Professional resulting in. STL and Polygon File Format (.PLY) files.

In both situations, 3D photography and taking nasal impression, the neonates were calm down by the parents and distracted to focus their attention as good as possible. Nevertheless, distraction should not result in facial expressions [25].

\section{Manual measurement and point-based analysis}

Three independent examiners (LMR, FG, MR) performed the manual measurements using 3dMDVultus 
(3dMDvultus $^{\text {mi }}$ Software 64-bit 2.4.1.4; 3dMD; USA). The analyzed landmarks, as well as the calculated 3D distances and angles are given in Tables 1 and 2 and are illustrated in Fig. 1.

In a first step, a mean point was calculated for each landmark and dataset and was used as a 3D analysis of reliability. Three dimensional distances and angles were automatically calculated based on the mean points for each dataset.

Finally, growth analysis in relation to the participant's age (days [d]) was conducted and visualized in graphs for each participant. Absolute information of growth is given in millimeters $[\mathrm{mm}]$ or degrees $\left[^{\circ}\right]$, the relative information of changes relate to the calculated differences between the measurements at $t=1 \mathrm{~d}$ and $\mathrm{t}=\mathrm{x}$ (i.e. the investigated point in time) and is given in percent [\%].

\section{Superimposition and surface-based, semi-automatic analysis}

In order to evaluate the accuracy of the described 3D facial scanner, a surface-based analysis was performed using Geomagic (Geomagic ${ }^{\circ}$ Control, Version 2014, USA). The integrated best-fit algorithm semi-automatically superimposed the control model and its corresponding facial scans. Second, the orthogonal distances between the surface points of the cast to the corresponding surface of the facial scan were registered and the Root Mean Squared (RMS) errors were calculated automatically. The resulting statistical reports of each model pair were subsequently combined in a single table for further analysis.

\section{Statistical analyses}

The data were analyzed with $\mathrm{IBM}^{\circ} \mathrm{SPSS}^{\circ} 25.0$ for Mac (IBM Corp, Armonk, NY, USA). Figures were generated

Table 1 Definitions of 21 analyzed landmarks as reported earlier by Farkas [44] and extended to the study analysis

\begin{tabular}{|c|c|}
\hline Abbreviation & Explanation \\
\hline$e x_{r} / 1$ & Exocanthion right / left \\
\hline$n$ & Nasion \\
\hline$e n_{r / 1}$ & Endocathion right / left \\
\hline prn & Pronasale \\
\hline$s b a l_{r / 1}$ & Subalare right / left \\
\hline sn & Subnasale \\
\hline$c^{\prime}$ & Highest point of the columella \\
\hline Is & Labiale superius \\
\hline$c h_{r / 1}$ & Cheilion right / left \\
\hline nost_post $r / 1$ & posterior border of nostril right / left \\
\hline nost_ant $r / 1$ & anterior border of nostril right / left \\
\hline nost_lat $r / 1$ & lateral border of nostril right / left \\
\hline nost_med $_{r / 1}$ & medial border of nostril right / left \\
\hline
\end{tabular}

with Excel $^{\bullet}$ (Microsoft Excel ${ }^{\bullet} 15.39$ for Mac, Microsoft Corp., Redmond, WA, USA).

The given $p$-values were calculated by two-tailed tests including Bonferroni correction and are subject to a global significance level of 0.05 .

\section{Results \\ Study collective}

The study collective consisted initially of 34 Caucasian neonates of whom 33 were observed and included for further analysis. The parents of one child ended the participation because of lack of time after two scans had already been taken. These two scans were excluded from our analysis due to the insufficient follow-up. Two parents did not allow taking an impression of their enrolled child. This resulted in 31 corresponding plaster models in total for the surface-based analysis and comparison between 3D photo and plaster model. Final gender distribution was homogenous including 16 males and 17 females.

\section{Growth analysis}

Mean 3D distances and angles, as well as mean absolute and relative growths are given in Tables 3 and 4. Figure 2 (A-D) illustrates the dimensional changes based on the extrapolated data. The error bars indicate 95\% confidence intervals.

\section{Nasal angles (Fig. 2a)}

The sagittal nasal tip angle $(n-n t-s n)$ showed a statistical significant increase of $5.92 \pm 1.02^{\circ}(5.1 \%) 120$ days postpartum.

Also the posterior nasal base angle $\left(s b a l_{r}-s n-s b a l_{l}\right)$ was found to significantly decrease by $4.67 \pm 1.29$ 。 (3.3\%) after 150 days.

All other measured angles did not reveal any statistically significant changes, even though a slight trend towards a change of approximately $-4^{\circ}$ after 150 days was found for the nasiolabial angle $\left(l s-s n-c^{\prime}\right)$, the anterior nasal base angle $\left(s b a l_{r}-n t-s b a l_{l}\right)$ as well as for the intercanthal angle $\left(e n_{r}-n-e n_{l}\right)$.

\section{Nasal parameters (Fig. 2b)}

The nose was observed to grow nearly linear in its longitudinal axis $(n-s n)$ with a statistical significant increase of approximately $6-7 \%$ per month during the first 90 days. Subsequent the growth rate decreased resulting in a total significant growth of $5.67 \pm 0.26 \mathrm{~mm}(27.2 \%)$ after 150 days. After 180 days an increased standard error of the mean value (SE) of $\pm 0.83 \mathrm{~mm}$ needs to be mentioned. The lateral nasal height $(e n-s b a l)$ showed similar growth rates with slightly higher growth rates during the first 60 days $(\sim 9 \%$ per month) resulting in a total growth of $6.26 \pm 0.27 \mathrm{~mm} \mathrm{(34.2 \% )}$ on the right, respectively $6.00 \pm 0.27 \mathrm{~mm}(32.6 \%)$ on the left side after 
Table 2 Definitions of 15 analyzed 3D distances and 6 angles

\begin{tabular}{|c|c|c|}
\hline & Abbreviation & Explanation \\
\hline \multirow[t]{12}{*}{ 3D distances } & $n-s n$ & nasal height \\
\hline & $e n_{r}-e n_{1}$ & intercanthal distance \\
\hline & $(e x-e n)_{r} / 1$ & eye width right / left \\
\hline & sbal-sbal, & subalar width \\
\hline & $s n-n t$ & nasal depth \\
\hline & $(e n-s b a l)_{r} / 1$ & lateral height of the nose right / left \\
\hline & $c^{\prime}-5 n$ & length of the columella \\
\hline & $s n-l s$ & lengt of the upper lip \\
\hline & $c h_{r}-c h_{1}$ & oral width \\
\hline & $(e n-c h)_{r} / 1$ & lateral height of the midface right / left \\
\hline & $(\text { nost_post - nost_ant) })_{r / 1}$ & length of the nostril right / left \\
\hline & $($ nost_lat - nost_med) $r / 1$ & width of the nostril right / left \\
\hline \multirow[t]{6}{*}{ 3D angles } & $n-n t-s n$ & nasal tip angle \\
\hline & Is $-s n-n t$ & subnasal angle \\
\hline & $I s-s n-c^{\prime}$ & approximated nasolabial angle \\
\hline & $s b a l_{r}-n t-s b a l_{1}$ & anterior angle of the nasal base triangle defined by the mentioned points \\
\hline & $s b a l_{r}-s n-s b a l_{1}$ & anterior angle of the nasal base triangle defined by the mentioned points \\
\hline & $e n_{r}-n-e n_{1}$ & anterior angle of the nasal root triangle defined by the mentioned points \\
\hline
\end{tabular}

150 days. The measurements at $t=180$ days postpartum also showed higher variances, resulting in non-significant changes in relation to the measurements at $t=150$ days postpartum (Table 3).

In the sagittal axis, the nasal depth $(s n-n t)$ was found to grow rapidly during the first 60 days with $1.39 \pm 0.21 \mathrm{~mm}$ (14.9\%) after 60 days, then leveling at an absolute growth of

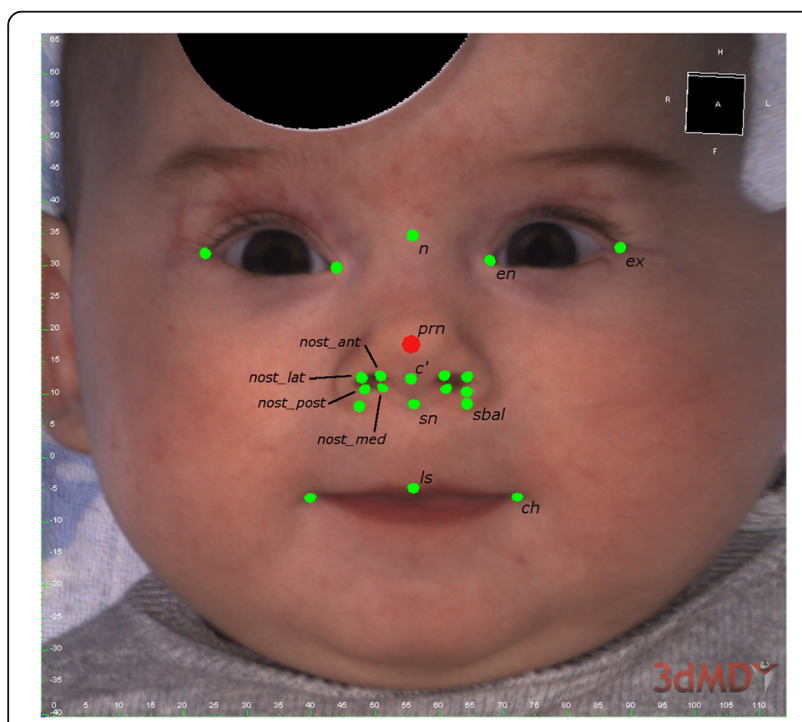

Fig. 1 Defined landmarks for point-based, 3D distance and angle analysis of the facial scan (FUEL3D ${ }^{\circledR}$ SCANIFY ${ }^{\circledR}$ system scanner) in frontal perspective using 3dMDVultus software (3dMDvultus ${ }^{\text {TM }}$ Software 64-bit 2.4.1.4; 3dMD ${ }^{\oplus}$; USA) (only one-sided legend and for abbreviations see also Table 1) approximately $1.6 \mathrm{~mm}(\sim 17 \%)$ in relation to the starting point until the end of the observation period. Significant differences between the different measurements were only found in relation to $t=1$ day. The columella was found to grow similarly with a total increase in length of $0.81 \pm$ $0.14 \mathrm{~mm}(19.5 \%)$ after 120 days. A first significant change was found for $t=60$ days in relation to the starting point, the following measurements did not show other statistically significant changes in between the measurements.

The basal nasal width $\left(s b a l_{r}-s b a l_{l}\right)$ seemed to increase rather slowly with a first statistically significant growth after 90 days $(1.74 \pm 0.36$; $10.8 \%)$ leveling at approximately $2 \mathrm{~mm}(\sim 12 \%)$. All other intervals did not show more statistically significant differences than in relation to the first day postpartum.

\section{Midfacial parameters (Fig. 2c)}

The lateral midfacial height $(e n-c h)$ showed an increase according to its central pendant of the nasal height with a steep increase of slightly more than $10 \%$ during the first 30 days, slowly flattening and reaching a growth of approximately $20 \%$ after 90 days, and approximately $27 \%$ after 150 days. Except for the measurements after 60 days the monthly intervals showed statistically significant differences to their previous values. Again the measurements at $t=180$ days postpartum showed higher variance.

The upper lip $(s n-l s)$ lengthened by approximately $1.7 \mathrm{~mm}$ in total (18.0\%) with a significant growth of $1.11 \pm 0.25 \mathrm{~mm}$ (12.1\%) during the first 30 days 


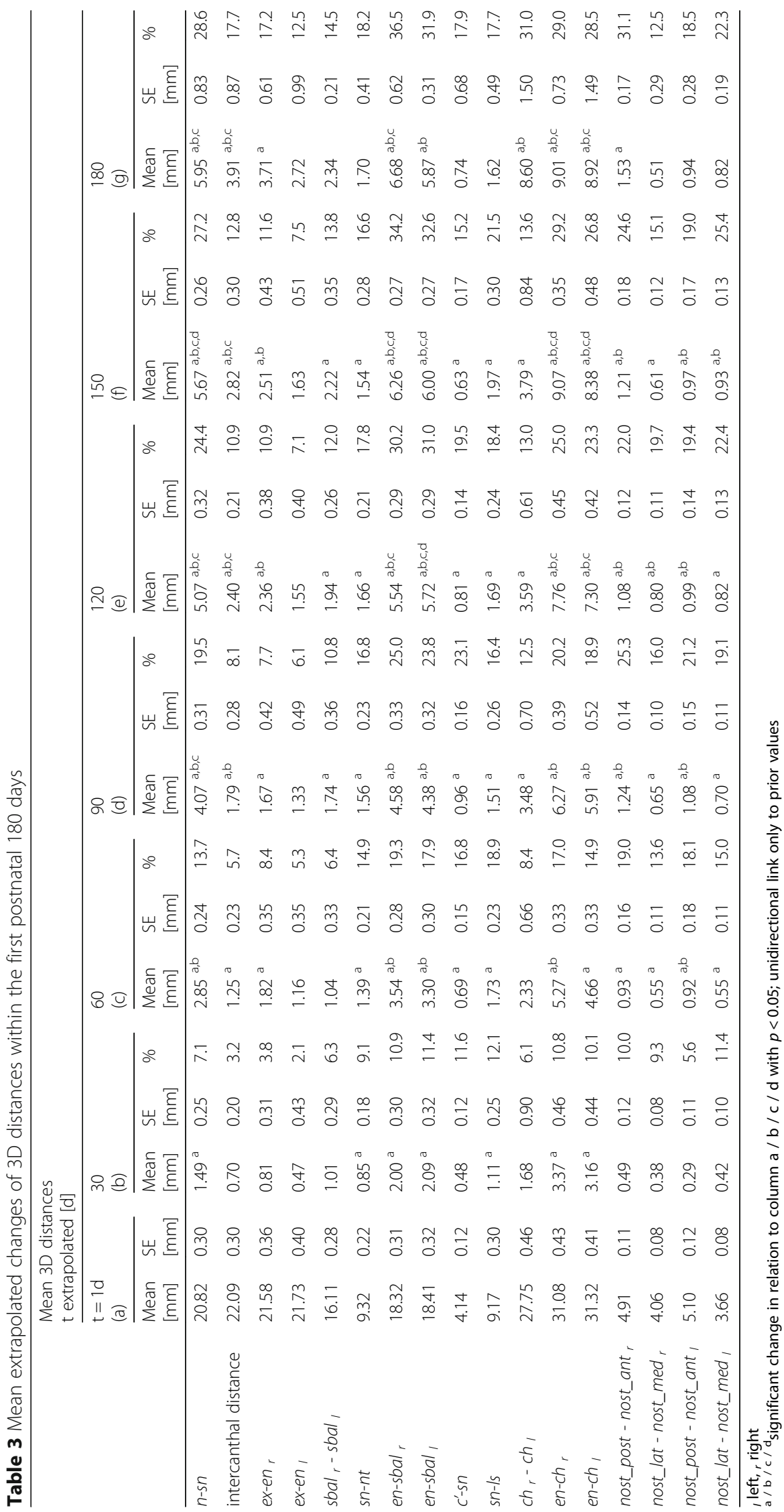




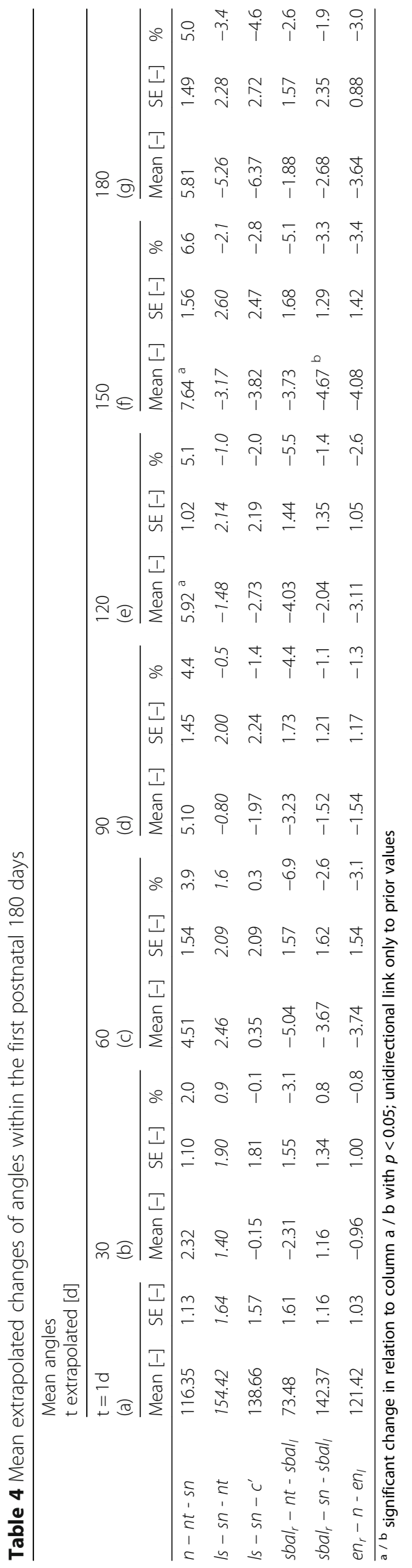




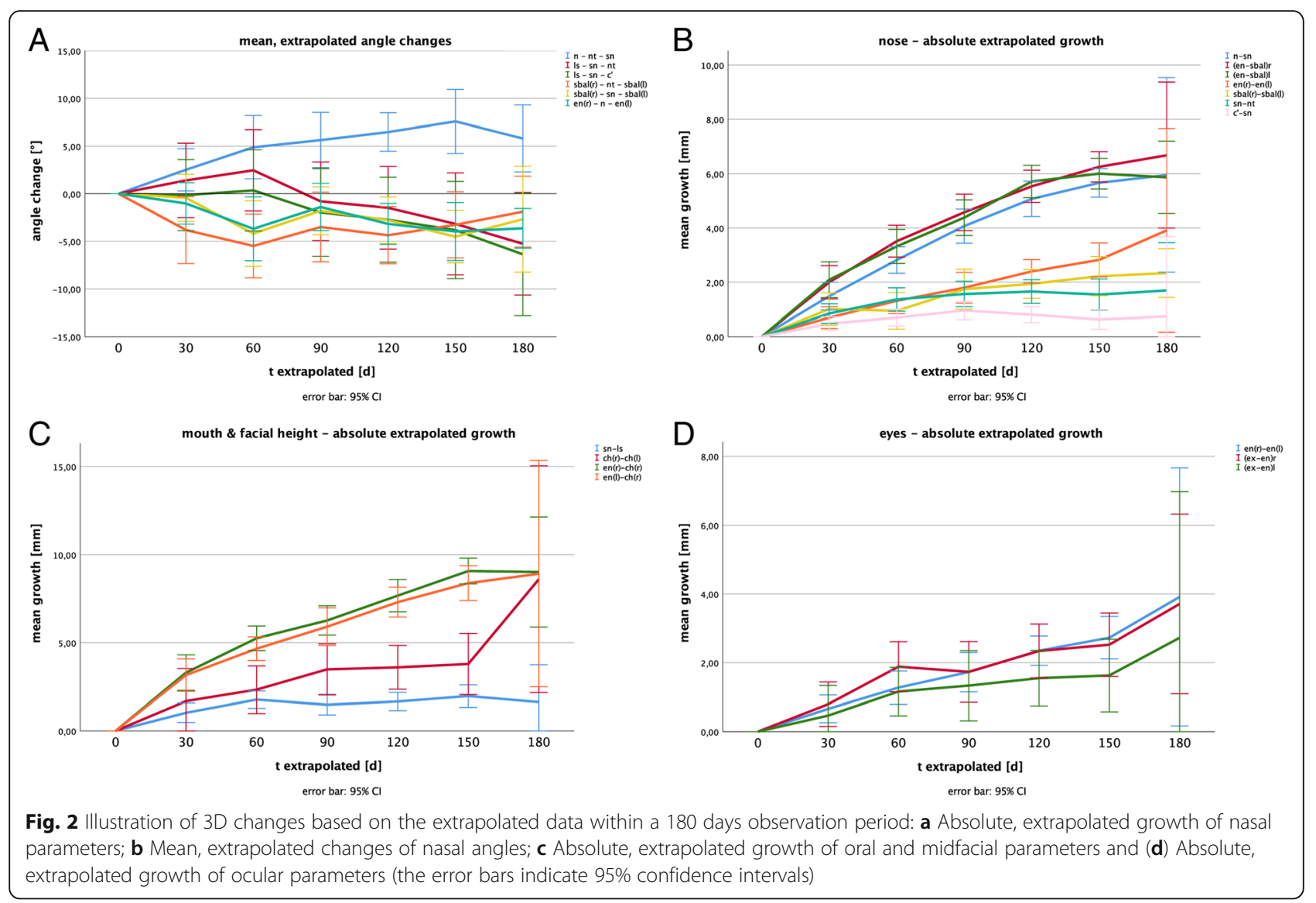

postpartum. The following intervals did not show other significant differences.

The oral width increased by $3.59 \pm 0.61 \mathrm{~mm}(13.0 \%)$ during the first 120 days. A first statistically significant difference was found for $t=90$ days postpartum. Comparisons of other intervals did not reveal more significant findings. The oral width at $\mathrm{t}=180$ days postpartum was found to show the highest spread of all values (growth of $8.60 \pm 1.50 \mathrm{~mm}$ ).

\section{Ocular parameters (Fig. 2d)}

Eye width and intercanthal distance were found to grow nearly linear with a significant increase of the intercanthal distance of $2.82 \pm 0.30 \mathrm{~mm}$ (12.8\%) after 150 days, and a significant growth of the right eye width of $2.51 \pm$ $0.43 \mathrm{~mm}(11.6 \%)$ after 150 days. For the left eye width, no significant growth could be registrated even though the measured distances were similar.

\section{Surface-based accuracy analysis}

Four. STL files of the corresponding plaster models were excluded because of heavy insufficiency of the impression. This resulted in 27 model pairs of age-matched corresponding. STL files (3D photo vs. plaster model).
Regarding all model pairs, the mean Root Mean Squared error (RMS error) was $0.72 \pm 0.22 \mathrm{~mm}$ between the superimposed surfaces.

The mean upper deviation was $0.51 \pm 0.14 \mathrm{~mm}$, the mean lower deviation was $-0.58 \pm 0.22 \mathrm{~mm}$ resulting in a mean standard deviation of $0.71 \pm 0.21 \mathrm{~mm}$.

Anatomical areas with rather severe curvature, overlapping surfaces or tangential point of view were found to show rather high deviation of the superimposed surface datasets (e.g. the posterolateral alar sidewalls, parts of the nostrils or the lower parts of the nasal tip). Representatively these areas are illustrated in Fig. 3.

\section{Discussion}

Conventional photo documentation of the face of neonates and children as well as of adults is well documented $[2,5]$. Taking impressions with different techniques and materials for detailed, reliable, safe and non-invasive 3D registration is the gold standard procedure and is also well described in the literature [22]. But preliminary, the authors want to highlight a relevant issue for the further interpretation of results. Direct methods which need contact to the patient's soft tissue to acquire 3D models, as seen in classical impression taking, might result in measurement errors caused by modification of the soft tissue, facial movement or 

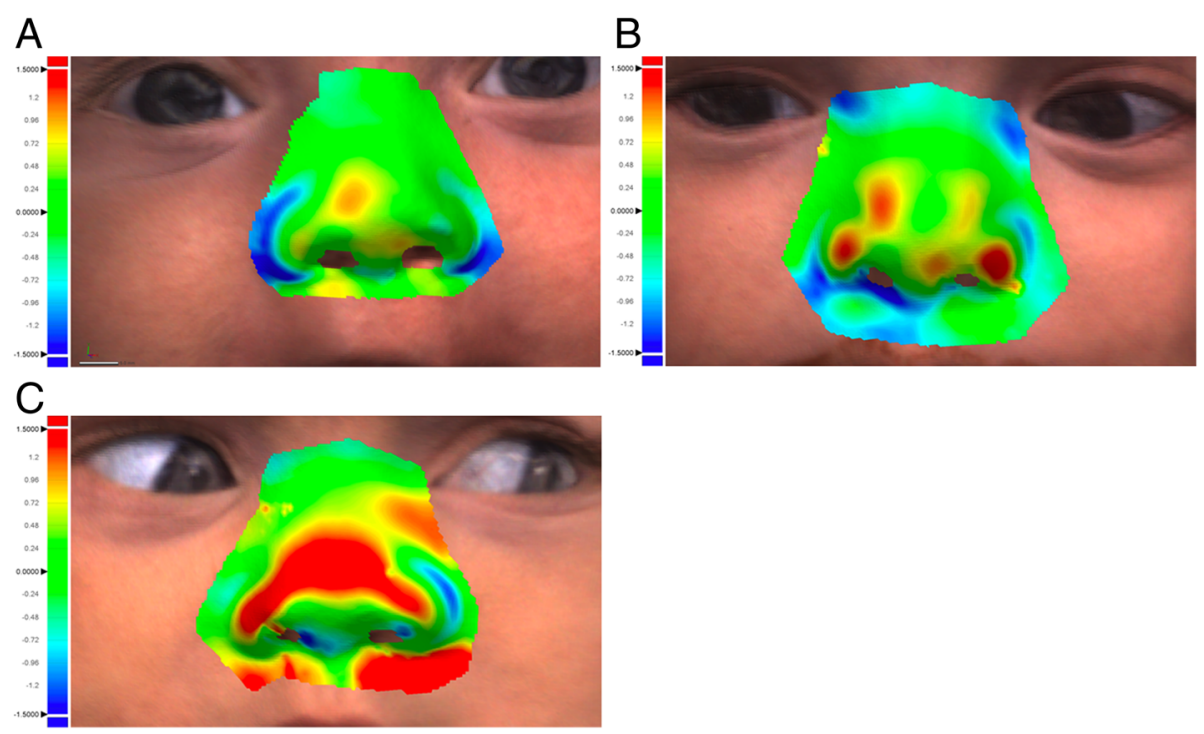

Fig. 3 The surface-based accuracy analysis with color-coded surface mismatch error using Geomagic (Geomagic ${ }^{\oplus}$ Control, Version 2014, USA) with a good (a), intermediate $(\mathbf{b})$ and insufficient $(\mathbf{c})$ result between calculated surface deviation of the corresponding .STL files 3D photo using the FUEL3D ${ }^{\circledast}$ SCANIFY $^{\circledR}$ system scanner versus plaster model

grimacing [26, 27]. Especially involuntary movements during taking impressions were relevant in our study and is also seen in our results. In four cases we could not include the plaster models, because of too low quality of the impressions due to movement of the children (Fig. 4). Further, impression materials and techniques, and plaster model generation might result in previously described inaccuracies in cast production [28]. For the mentioned reasons we preferred to use A-silicone as material and produced the plaster model within 1 hour [22]. Additionally, scanning
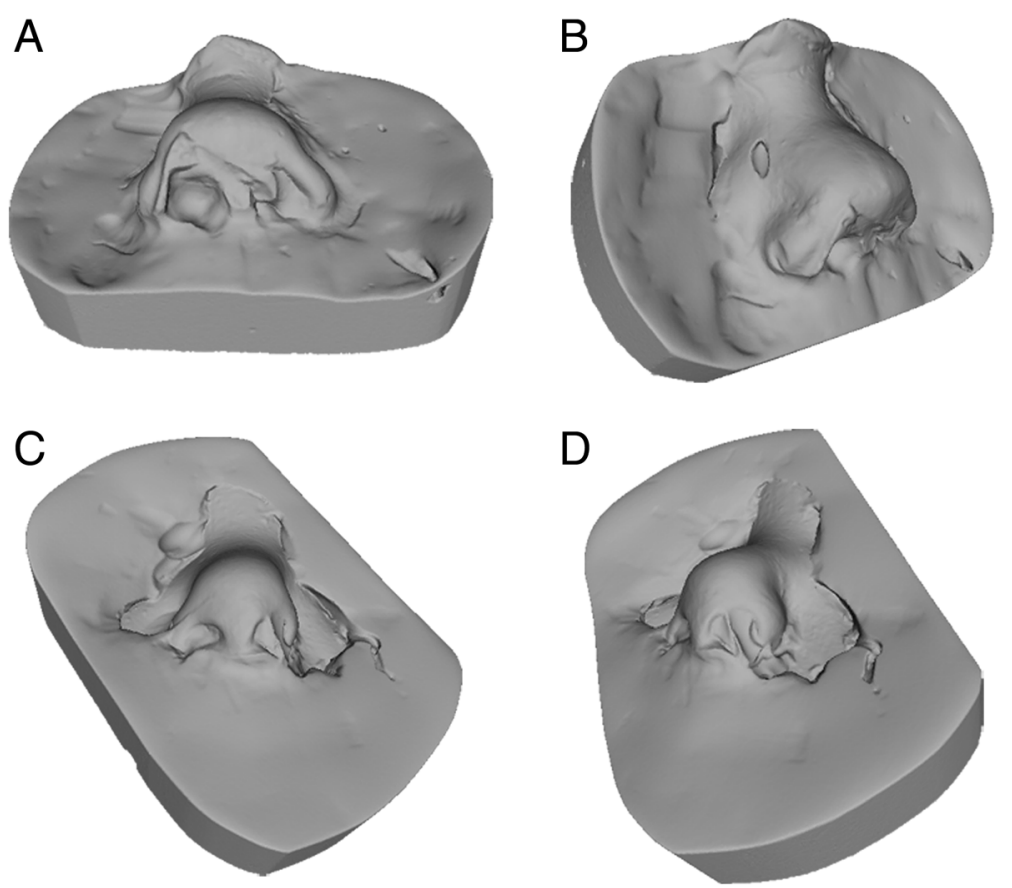

Fig. 4 Two exemplary cases of excluded plaster models because of low quality of impression and consecutive plaster model generation. As seen in caudal view (a and $\mathbf{c}$ ) and in latero-caudal view alar (b and $\mathbf{d}$ ) nose regions remained demanding. Further, correct and sufficient impressions of the nostrils are also difficult 
procedure of dental casts is also associated with inaccuracies, which cannot be neglected. In our study we used a common dental scanner with an accuracy of $20 \mu \mathrm{m}$. In summary, the indirect way of surface information acquisition is always associated with possible theoretical errors $[23,29]$. For that reason, the. STL file of the 3D photography was rather compared to the resulting. STL file of the plaster model than to the theoretical "truth". On the other hand, studies comparing only $3 \mathrm{D}$ photos compare only the "theoretical truth" with all the inaccuracies of the used systems [21].

In clinical translation, especially in neonates and young children, taking impressions remains challenging and therefore clinically feasible and reliable alternatives are wanted for sufficient registration, follow-up and treatment planning. For the purpose of non-invasive extraoral registration, 3D photography is becoming more popular and several studies imply a better assessment of cleft-related deformities than in conventional 2D photography [30, 31]. The analyzed facial scanner (FUEL3D ${ }^{\circ}$ SCANIFY $^{\circ}$ system scanner) had a user-friendly interface and the associated software was easy to use. Regarding the acquisition costs, the FUEL3D ${ }^{\circ}$ SCANIFY $^{\circ}$ system scanner is a low-cost 3D surface scanner.

In comparison to other portable systems, our analyzed device had a comparable, acceptable, low RMS error of $0.72 \pm 0.22 \mathrm{~mm}[16,20,21]$. Even in comparison to reported results of stationary photogrammetry systems like 3dMDface or Vectra, our RMS error seems to be acceptable and keeps up with these systems [32-34]. Fan et al. also analyzed a low-cost 3D Scanner (\$400). But in contrast to our good results, they reported an overall Target Resulting Error of $2.5 \pm 0.31 \mathrm{~mm}$ [35]. This is worse than our results and is on the border for clinical relevance, since deviations larger than $2 \mathrm{~mm}$ are considered unreliable.

Our results are in three ways interesting and worthwhile to follow. First, RMS error is comparable to above-mentioned systems, but the analyzed FUEL3D ${ }^{\circ}$ SCANIFY ${ }^{\circ}$ system scanner costs only about $1500 €$. This is far less than a 3dMD system or other described handheld solutions. Three-dimensional photo documentation could be affordable even for smaller clinics/institutions or in private practice with this system. Second, deviation of more than $2 \mathrm{~mm}$ is considered to be unreliable and the assessment of areas with high curvatures and shadows can be difficult $[19,36]$. In contrast to other studies, the corresponding models in the third month of life (3D photo vs. plaster model) only captured the probably most demanding anatomical area of the face, the perinasal region. Nevertheless, our results remained good. And last, the evaluated 3D system is the very fast capture speed of approximately $0.1 \mathrm{~s}$ per picture. The resulting $3 \mathrm{D}$ photo is a single $3 \mathrm{D}$ photograph and is not based on a sequence of 3D pictures as seen in the Artec Eva scanner for example [16]. This enables an unaltered picture, even in cases of involuntary facial movements during surface recognition or scanning as stated earlier [37]. Nevertheless, even in our collective the most varying landmarks and corresponding 3D distance were cheilion right/left and the oral width at 180 days postpartum which was associated with the highest spread of all values (growth of $8.60 \pm 1.50 \mathrm{~mm}$ ). Mouth movements of the newborn might explain these findings. An already described solution is the capturing of a video sequence, as done with 3dMDface or Artec Eva system for example. But herein, the volume of data increases significantly and detailed surface data could get lost during post-processing procedures [16]. On the other hand, anatomical areas with rather severe curvature or overlapping surfaces were found to show higher deviations in our best-fit analysis of the superimposed surfaces. This might be due to the vertical location of the two integrated cameras in the evaluated system and their rather small distance to each other compared to stationary scanners. To optimize the results, a third camera may improve the accuracy.

We analyzed neonates within the first 180 days of life. As mentioned earlier, facial surface registration is challenging in this cohort. This is not the first study of neonates/newborn using 3D systems and scanner. But most 3D photogrammetry systems were only used to perform a descriptive analysis of the post-operative result for example after primary lip repair in children with cleft lip and palate or in patients with craniosynostosis [11-14]. Our study analyzed the growth of the perinasal region in healthy unaffected newborn. These results can be used as a 3D data set of the optimal perinasal region and its development. As described by others, the major deformity for example in patients with cleft lip and palate results in the nose and secondarily in the midfacial region [38]. For this purpose the knowledge of healthy growth is important and in the age of virtualization additional information to the conventional 2D photography is needed [39]. 3D photography is nowadays possible with an accurate quality and can be used for documentation, even with portable solutions. But according to Kuijpers et al. no data have yet been able to show that 3D methods are more informative than conventional $2 \mathrm{D}$ methods [40]. Chou et al. fully agreed with us in seeing the benefits of consecutive integration of $3 \mathrm{D}$ photo documentation in children. They documented prospectively the growth of neonates with unilateral cleft lip and palate during nasoalveolar molding (NAM) therapy with weekly photographs [15]. No impressions were needed. According to our experience with NAM [41], the therapy can be easier adopted, when 3D models are present. This eases the follow-up and can also be used to show the 
instant therapeutic effect to the parents, which might further improve the mandatory compliance for this therapy.

In a next step we plan to integrate the extraoral three-dimensional data to further improve our final goal, the automated production of NAM plates using the CAD/ CAM technique as described earlier [42, 43]. Further we will continue the observation of our included children in order to generate a systematic reference pool for the growing face, based on 3D photographical data acquisition.

\section{Limitations}

One limitation of the study is, that only one 3D system or scanner was used. But according to the literature, plaster models of good impressions remain the gold standard. Classical anthropometry with real-time measurement would not have been feasible and a surface analysis would have been impossible in neonates. Another limitation might the fact that only one corresponding plaster model was used for comparison. But the regional ethical review board of the technical university of Munich only approved one perinasal impression in the healthy neonates at the age of 3 months. Last, the RMS error represents only the difference between the compared. STL files of the resulting scans and not necessarily between the real perinasal region and the $3 \mathrm{D}$ photo.

\section{Conclusions}

The low-budget FUEL3D ${ }^{\circ}$ SCANIFY $^{\ominus}$ system scanner seems to have acceptable accuracy compared to other established systems and is feasible to use despite its technical simplicity. Severe curvature and overlapping surfaces are associated with greater inaccuracy because of its vertical orientation of the integrated two cameras. 3D growth analyses were easily possible and enabled us to establish a optimal 3D data set of the developing midfacial region. The cost-effectiveness of the system is suitable for most common applications with regard to facial scans in neonates.

\section{Abbreviations}

.PLY file: Polygon File Format file; STL file: Standard Tessellation Language file; 2D: two-dimensional; 3D : three-dimensional; RMS error: Root Mean Squared error

\section{Acknowledgements}

All other persons who have contributed to the study are listed as authors, since everyone has met the listed criteria for authorship.

This study is part of the doctoral theses of Fabienna Mittermeier and Maximilian Roth

\section{Funding}

The study is part of the "RapidNAM" project and has been funded by the non-profit Zeidler-Forschungs-Stiftung, Waldkraiburg, Germany.

\section{Availability of data and materials}

All data generated or analysed during this study are included in this published article.

\section{Authors' contributions}

LMR: conception, conduction, analysis, major contributor in writing the manuscript. MR: conduction, analysis, statistics. AMF: statistics, review manuscript, illustrations. FM: fotography, impression taking, statistics. BK: screening examinations (U1 and U2) for enrollement. K-DW: conception, interpretation results. FDG: conception, conduction, analysis, major contributor in writing the manuscript. DJL: conception, interpretation results, major contributor in writing the manuscript. All authors read and approved the final manuscript

\section{Ethics approval and consent to participate}

The study followed the Declaration of Helsinki on medical protocol and ethics and the regional Ethical Review Board of the technical university of Munich approved the study (approval number: 13/16 S).

\section{Consent for publication}

Written participant consent was obtained from the parents and the data collected were pseudonymized.

\section{Competing interests}

The authors declare that they have no competing interests.

\section{Publisher's Note}

Springer Nature remains neutral with regard to jurisdictional claims in published maps and institutional affiliations.

\section{Author details}

'Department of Oral and Maxillofacial Surgery, Klinikum rechts der Isar, Technische Universität München, Ismaningerstr. 22, D-81675 Munich, Germany. ${ }^{2}$ Department of Oral and Maxillofacial Surgery, Helios Klinikum München West, Munich, Germany. ${ }^{3}$ Section of Obstetrics, Frauenklinik, Klinikum rechts der Isar, Technische Universität München, Munich, Germany.

Received: 31 March 2018 Accepted: 26 July 2018

Published online: 03 August 2018

\section{References}

1. Freeman AK, Mercer NS, Roberts LM. Nasal asymmetry in unilateral cleft lip and palate. J Plast Reconstr Aesthet Surg. 2013;66:506-12.

2. Asher-McDade C, Roberts C, Shaw WC, Gallager C. Development of a method for rating nasolabial appearance in patients with clefts of the lip and palate. Cleft Palate Craniofac J. 1991;28:385-90. discussion 390-381

3. Spolyar JL, Roldan JC. Changes in nose symmetry in unilateral cleft lip and palate treated by differing pre-surgical assistance: an objective assessment of primary repair. J Craniomaxillofac Surg. 2015;43:779-89.

4. Mosmuller D, Tan R, Mulder F, Bachour Y, de Vet H, Don GP. The use and reliability of SymNose for quantitative measurement of the nose and lip in unilateral cleft lip and palate patients. J Craniomaxillofac Surg. 2016:44: $1515-21$.

5. Farkas $L G$, Bryson W, Klotz J. Is photogrammetry of the face reliable? Plast Reconstr Surg. 1980;66:346-55.

6. Nord F, Ferjencik R, Seifert B, Lanzer M, Gander T, Matthews F, Rucker M, Lubbers HT. The 3dMD photogrammetric photo system in craniomaxillofacial surgery: validation of interexaminer variations and perceptions. J Craniomaxillofac Surg. 2015;43:1798-803.

7. Aboul-Hosn Centenero S, Hernandez-Alfaro F. 3D planning in orthognathic surgery: CAD/CAM surgical splints and prediction of the soft and hard tissues results - our experience in 16 cases. J Craniomaxillofac Surg. 2012;40: $162-8$.

8. Van Hemelen G, Van Genechten M, Renier L, Desmedt M, Verbruggen E, Nadjmi N. Three-dimensional virtual planning in orthognathic surgery enhances the accuracy of soft tissue prediction. J Craniomaxillofac Surg. 2015;43:918-25.

9. Ozsoy U. Comparison of different calculation methods used to analyze facial soft tissue asymmetry: global and partial 3-dimensional quantitative evaluation of healthy subjects. J Oral Maxillofac Surg. 1847;2016(74):e1841-9.

10. Berlin NF, Berssenbrugge $P$, Runte $C$, Wermker $K$, Jung $S$, Kleinheinz J, Dirksen D. Quantification of facial asymmetry by $2 \mathrm{D}$ analysis - a comparison of recent approaches. J Craniomaxillofac Surg. 2014;42:265-71.

11. Linden OE, Taylor HO, Vasudavan S, Byrne ME, Deutsch CK, Mulliken JB, Sullivan SR. Three-dimensional analysis of nasal symmetry following primary 
correction of unilateral cleft lip nasal deformity. Cleft Palate Craniofac J. 2017:54:715-9.

12. Al-Rudainy D, Ju X, Mehendale F, Ayoub A. Assessment of facial asymmetry before and after the surgical repair of cleft lip in unilateral cleft lip and palate cases. Int J Oral Maxillofac Surg. 2018;47(3):411-9.

13. Alazzawi O, Morioka D, Miyabe M, Tosa Y, Ohkubo F, Yoshimoto S. Nasolabial growth in individuals with unilateral cleft lip and palate: a preliminary study of longitudinal observation using three-dimensional Stereophotogrammetry. J Craniofac Surg. 2017;28:e449-51.

14. Tenhagen M, Bruse JL, Rodriguez-Florez N, Angullia F, Borghi A, Koudstaal MJ, Schievano S, Jeelani O, Dunaway D. Three-dimensional handheld scanning to quantify head-shape changes in spring-assisted surgery for sagittal Craniosynostosis. J Craniofac Surg. 2016;27:2117-23.

15. Chou PY, Hallac RR, Ajiwe T, Xie XJ, Liao YF, Kane AA, Park YJ. The role of Nasoalveolar molding: a 3D prospective analysis. Sci Rep. 2017;7:9901.

16. Modabber A, Peters F, Kniha K, Goloborodko E, Ghassemi A, Lethaus B, Holzle F, Mohlhenrich SC. Evaluation of the accuracy of a mobile and a stationary system for three-dimensional facial scanning. J Craniomaxillofac Surg. 2016;44:1719-24.

17. Metzler P, Sun Y, Zemann W, Bartella A, Lehner M, Obwegeser JA, KruseGujer AL, Lubbers HT. Validity of the 3D VECTRA photogrammetric surface imaging system for cranio-maxillofacial anthropometric measurements. Oral Maxillofac Surg. 2014;18:297-304.

18. Yamamoto S, Miyachi H, Fujii H, Ochiai S, Watanabe S, Shimozato K. Intuitive Facial Imaging Method for Evaluation of Postoperative Swelling: A Combination of 3-Dimensional Computed Tomography and Laser Surface Scanning in Orthognathic Surgery. J Oral Maxillofac Surg. 2016;74:2506 e2501-10.

19. Knoops PG, Beaumont CA, Borghi A, Rodriguez-Florez N, Breakey RW, Rodgers W, Angullia F, Jeelani NU, Schievano S, Dunaway DJ. Comparison of three-dimensional scanner systems for craniomaxillofacial imaging. J Plast Reconstr Aesthet Surg. 2017;70:441-9.

20. Camison L, Bykowski M, Lee WW, Carlson JC, Roosenboom J, Goldstein JA, Losee JE, Weinberg SM. Validation of the Vectra H1 portable threedimensional photogrammetry system for facial imaging. Int J Oral Maxillofac Surg. 2018:47(3):403-40.

21. Gibelli D, Pucciarelli V, Cappella A, Dolci C, Sforza C. Are portable stereophotogrammetric devices reliable in facial imaging? A validation study of VECTRA H1 device. J Oral Maxillofac Surg. 2018. In press.

22. Loeffelbein DJ, Rau A, Wolff KD. Impression technique for monitoring and virtual treatment planning in nasoalveolar moulding. $\mathrm{Br} J$ Oral Maxillofac Surg. 2013;51:898-901.

23. Thongthammachat S, Moore BK, Barco MT 2nd, Hovijitra S, Brown DT, Andres CJ. Dimensional accuracy of dental casts: influence of tray material, impression material, and time. J Prosthodont. 2002;11:98-108.

24. About FUEL3D. https://www.fuel-3d.com/about-fuel3d/.

25. Heike CL, Upson K, Stuhaug E, Weinberg SM. 3D digital stereophotogrammetry: a practical guide to facial image acquisition. Head Face Med. 2010:6:18

26. Tzou CH, Artner NM, Pona I, Hold A, Placheta E, Kropatsch WG, Frey M. Comparison of three-dimensional surface-imaging systems. J Plast Reconstr Aesthet Surg. 2014;67:489-97.

27. Kook MS, Jung S, Park HJ, Oh HK, Ryu SY, Cho JH, Lee JS, Yoon SJ, Kim MS, Shin HK. A comparison study of different facial soft tissue analysis methods. J Craniomaxillofac Surg. 2014;42:648-56.

28. Wassell RW, Abuasi HA. Laboratory assessment of impression accuracy by clinical simulation. J Dent. 1992;20:108-14.

29. Holberg C, Schwenzer K, Mahaini L, Rudzki-Janson I. Accuracy of facial plaster casts. Angle Orthod. 2006;76:605-11.

30. Mosmuller DG, Griot JP, Bijnen CL, Niessen FB. Scoring systems of cleftrelated facial deformities: a review of literature. Cleft Palate Craniofac J. 2013;50:286-96.

31. Al-Omari I, Millett DT, Ayoub AF. Methods of assessment of cleft-related facial deformity: a review. Cleft Palate Craniofac J. 2005;42:145-56

32. Jayaratne YS, McGrath CP, Zwahlen RA. How accurate are the fusion of cone-beam CT and 3-D stereophotographic images? PLoS One. 2012;7: e49585.

33. Lin CY, Hsung TC, Khambay B. Reducing cone beam CT scan height as a method of radiation reduction for photorealistic three-dimensional orthognathic planning. J Craniomaxillofac Surg. 2015;43:907-12.
34. Choi JW, Lee JY, Oh TS, Kwon SM, Yang SJ, Koh KS. Frontal soft tissue analysis using a 3 dimensional camera following two-jaw rotational orthognathic surgery in skeletal class III patients. J Craniomaxillofac Surg. 2014:42:220-6.

35. Fan $Y, X u X$, Wang M. A surface-based spatial registration method based on sense three-dimensional scanner. J Craniofac Surg. 2017;28:157-60.

36. Aung SC, Ngim RC, Lee ST. Evaluation of the laser scanner as a surface measuring tool and its accuracy compared with direct facial anthropometric measurements. Br J Plast Surg. 1995;48:551-8.

37. Lubbers HT, Medinger L, Kruse AL, Gratz KW, Obwegeser JA, Matthews F. The influence of involuntary facial movements on craniofacial anthropometry: a survey using a three-dimensional photographic system. $\mathrm{Br}$ J Oral Maxillofac Surg. 2012;50:171-5.

38. Chaisrisookumporn N, Stella JP, Epker BN. Anthropometric profile evaluation of the midface in patients with cleft lip and palate. Oral Surg Oral Med Oral Pathol Oral Radiol Endod. 1995;80:127-36.

39. Kluba S, Bopp C, Bacher M, Reinert S, Krimmel M. Morphological analysis of the lip and nose following cleft lip repair with simultaneous partial primary rhinoplasty: a prospective study over 4 years. J Craniomaxillofac Surg. 2015; 43:599-605.

40. Kuijpers MA, Chiu YT, Nada RM, Carels CE, Fudalej PS. Three-dimensional imaging methods for quantitative analysis of facial soft tissues and skeletal morphology in patients with orofacial clefts: a systematic review. PLoS One. 2014;: $:$ e93442.

41. Rau A, Ritschl LM, Mücke T, Wolff K-D, Loeffelbein DJ. Nasoalveolar molding in cleft care-experience in 40 patients from a single Centre in Germany. PLoS One. 2015;10:e0118103.

42. Bauer FX, Schönberger M, Gattinger J, Eblenkamp M, Wintermantel E, Rau A, Güll FD, Wolff K-D, Loeffelbein DJ. RapidNAM: generative manufacturing approach of nasoalveolar molding devices for presurgical cleft lip and palate treatment. Biomed Tech (Berl). 2017;62:407-14.

43. Ritschl LM. Rau a, Güll FD, diBora B, Wolff K-D, Schönberger M, Bauer FX, Wintermantel E, Loeffelbein DJ. Pitfalls and solutions in virtual design of nasoalveolar molding plates by using CAD/CAM technology-a preliminary clinical study. J Craniomaxillofac Surg. 2016:44:453-9.

44. Farkas LG: Anthropometry of the head and face: raven press; 1994.
Ready to submit your research? Choose BMC and benefit from:

- fast, convenient online submission

- thorough peer review by experienced researchers in your field

- rapid publication on acceptance

- support for research data, including large and complex data types

- gold Open Access which fosters wider collaboration and increased citations

- maximum visibility for your research: over $100 \mathrm{M}$ website views per year

At BMC, research is always in progress.

Learn more biomedcentral.com/submissions 